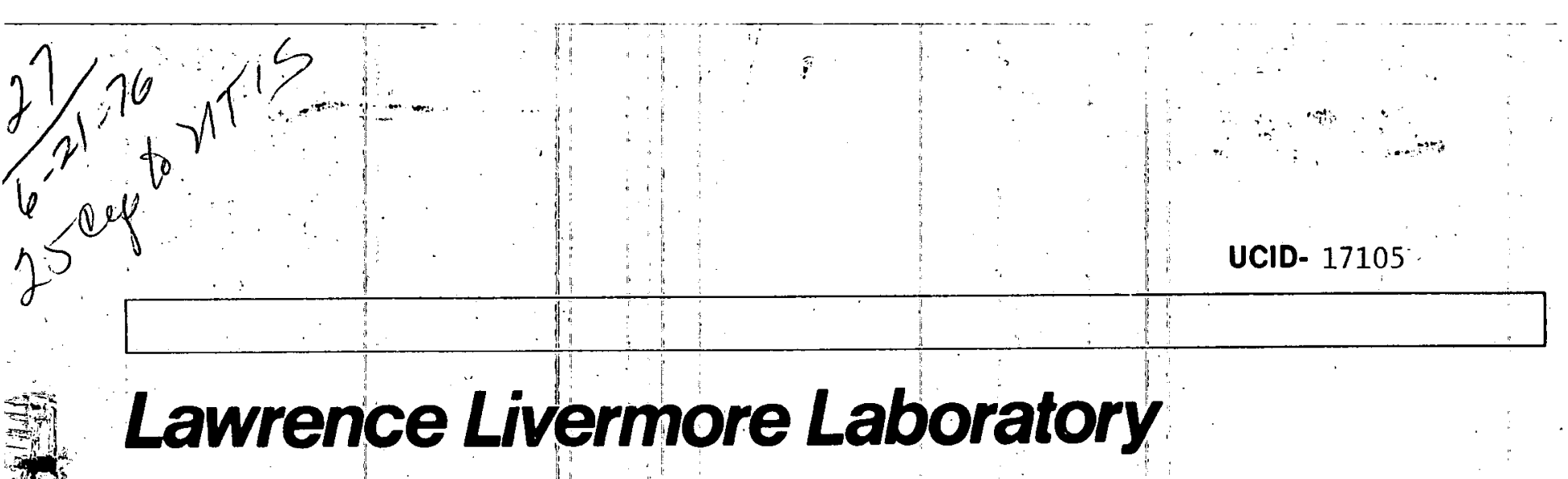

BAUSCHINGER EFFECT IN URANIUM

S. G. Cochran

M. W. Guinan

MASTER

March 17, 1976
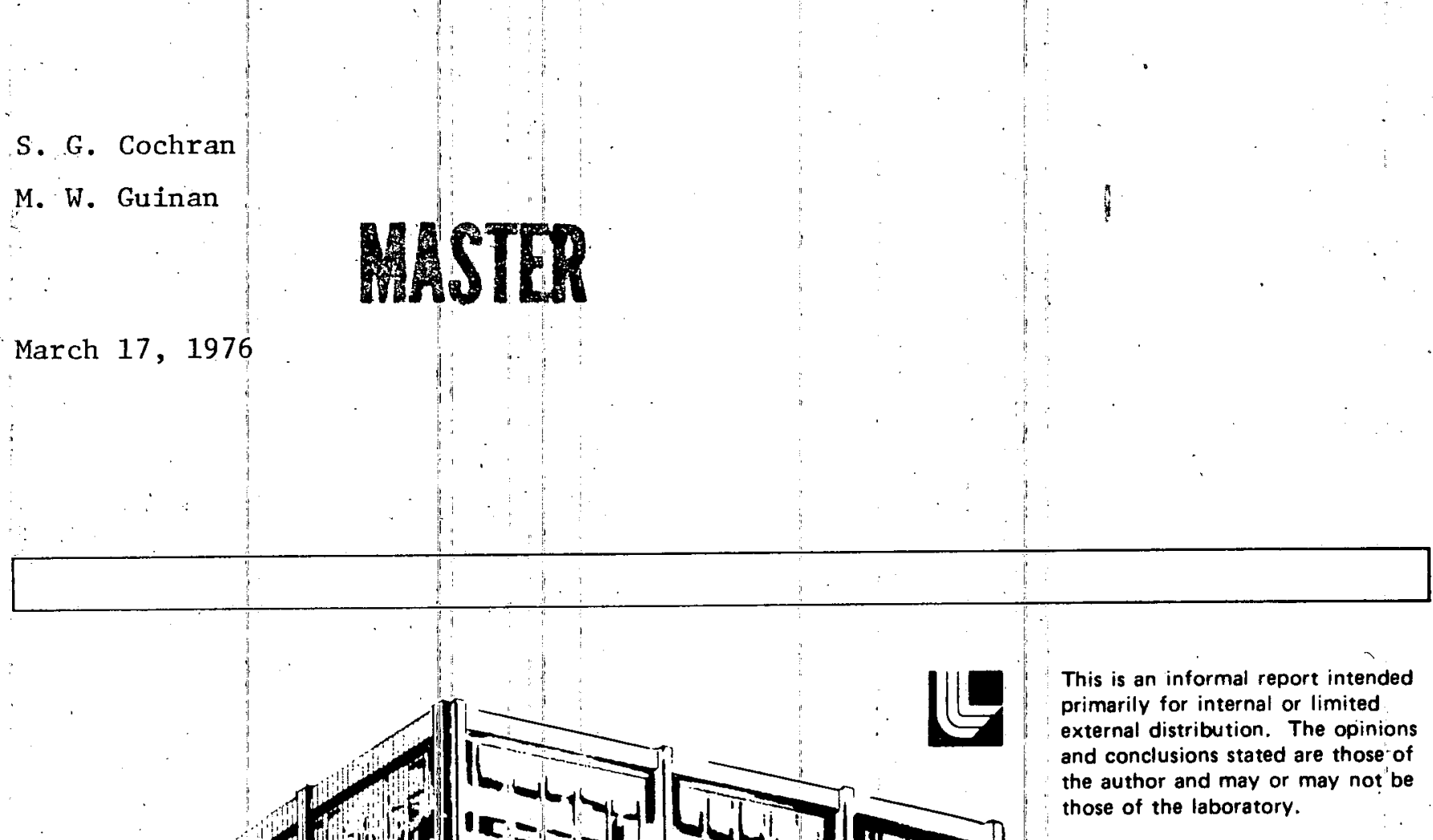

Prepared for U.S. Energy Research \& Development Administration under contract No. W-7405-Eng-48.

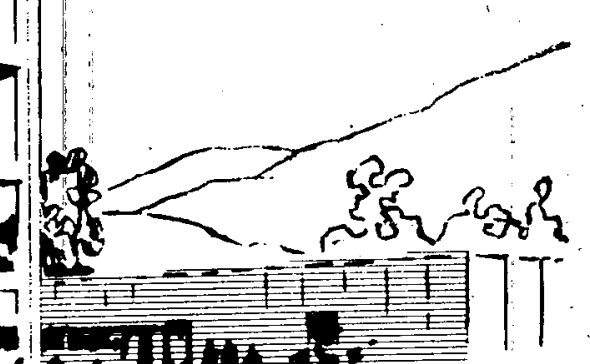




\section{DISCLAIMER}

This report was prepared as an account of work sponsored by an agency of the United States Government. Neither the United States Government nor any agency Thereof, nor any of their employees, makes any warranty, express or implied, or assumes any legal liability or responsibility for the accuracy, completeness, or usefulness of any information, apparatus, product, or process disclosed, or represents that its use would not infringe privately owned rights. Reference herein to any specific commercial product, process, or service by trade name, trademark, manufacturer, or otherwise does not necessarily constitute or imply its endorsement, recommendation, or favoring by the United States Government or any agency thereof. The views and opinions of authors expressed herein do not necessarily state or reflect those of the United States Government or any agency thereof. 


\section{DISCLAIMER}

Portions of this document may be illegible in electronic image products. Images are produced from the best available original document. 


\title{
BAUSCHINGER EFFECT IN URANIUM
}

\author{
S. G. Cochran \\ M. W. Guinan
}

\section{ABSTRACT}

We have measured the Bauschinger effect in uranium and developed a model of the effect for use in one-dimensional hydrodynamic codes. Our results from plate-impact tests show that rarefaction waves in uranium can be calculated more accurately with this model. We conclude that the Bauschinger effect can be an important aspect of rarefaction waves in uranium and other materials.

\section{INTRODUCTION}

The Bauschinger effect is the phenomenon that elastic-plastic materials behave differently upon unloading than when they were loaded. Figure 1 shows this effect schematically, with stress deviator plotted against strain deviator. Curve $I$ depicts ideal behavior of a work-hardening elastic-plastic material. The material behaves elastically with shear modulus $G_{0}$ until it yields; then plastic flow occurs. When the strain rate is reversed, the release path is again elastic until reverse yield occurs at the previous yield value. Although most metals load in an approximately ideal way, many show some departures from the ideal unloading curve, as curve 2 shows. Curve 2 depicts two important aspects of the Bauschinger effect. The first is that the release path is not elastic; the second, that the reverse flow stress does not reach the ideal yield value until considerable reverse flow has occurred. Thus, the release path differs significantly from the ideal release path. In the ideal case, plastic strain is totally irreversible, while elastic strain can be recovered. The Bauschinger effect removes this clear distinction.

We study the Bauschinger effect because we need to understand release (or rarefaction) waves in metals. Such waves are important in spall, for example. ${ }^{2}$ Consider a symmetric plate impact experiment: a uranium flyer plate strikes a uranium target plate at a velocity u (Fig. 2a). Figure 2b 


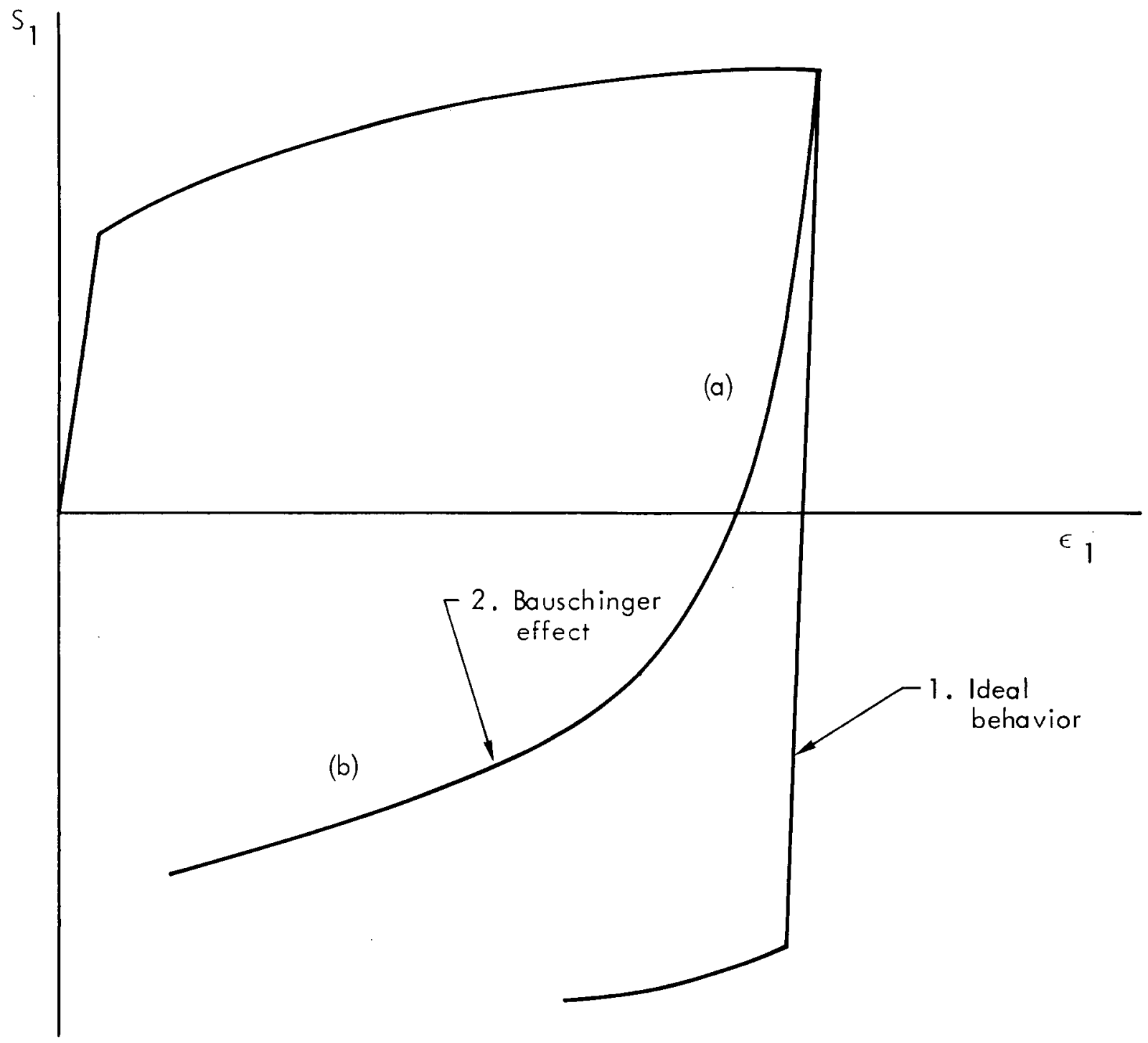

Fig. 1. Schematic of elastic-plastic behavior. Curve 1 is the ideal elasticplastic path; curve 2 shows the Bauschinger effect. In curve 2, the part labeled (a) shows that release is not elastic; the part labeled (b) shows that reload flow stress is reduced. We use a principal stress coordinate system in which three diagonal elements of the stress tensor can be non-zero. $S_{1}$, $\varepsilon_{1}$ refer to the largest deviator stress and strain, respectively, in magnitude. For the definitions of stress and strain deviator, see, for example, Ref. 1. 


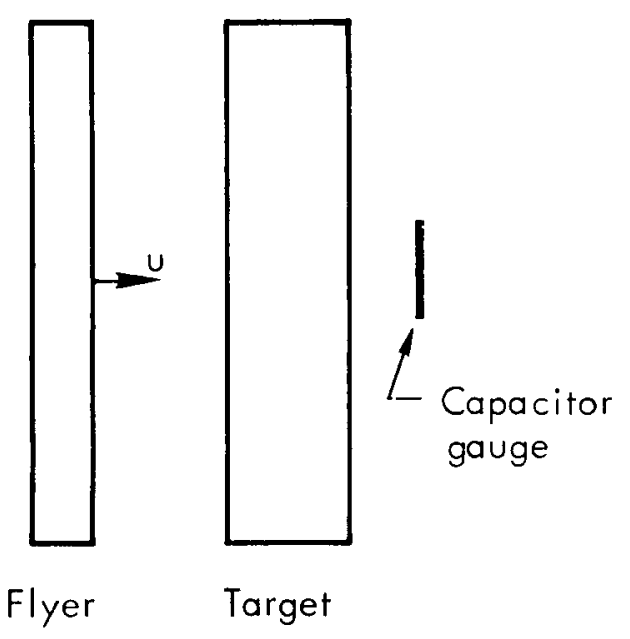

(a)

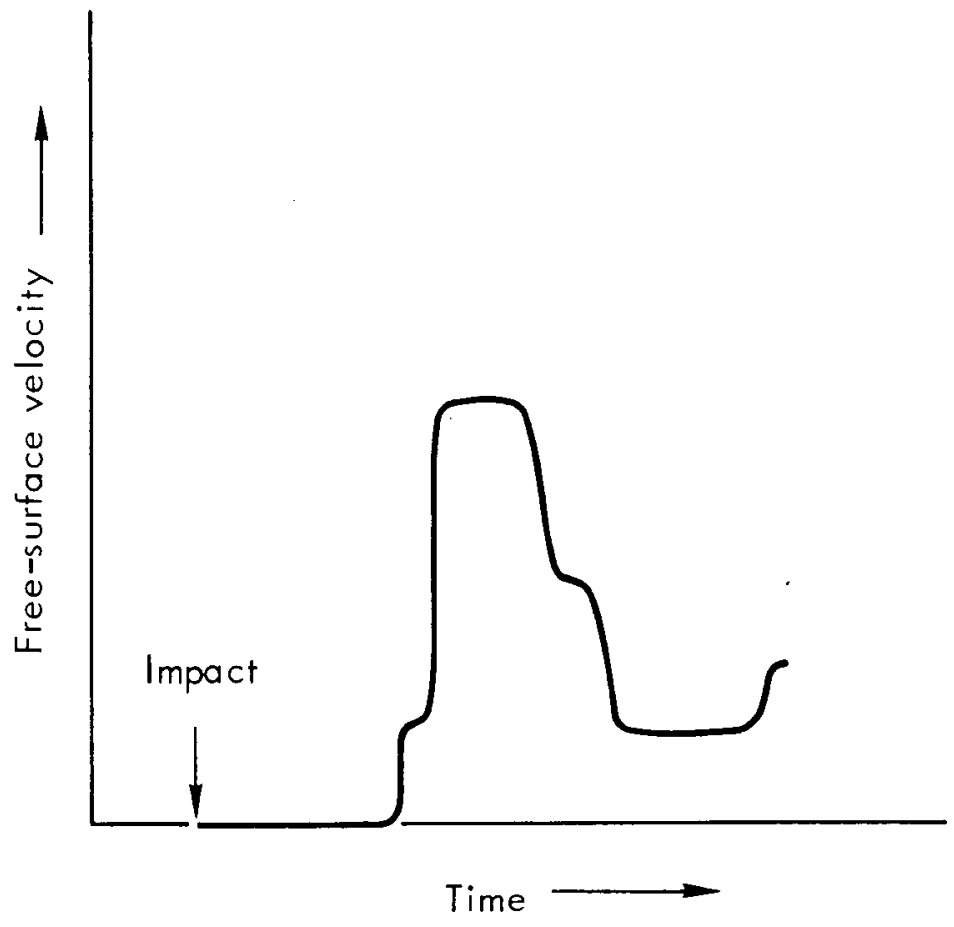

(b)

Fig. 2. Example response of an ideal elastic-plastic material in a plateimpact experiment. (a) shows the flyer plate hitting the target at velocity $u$; (b) shows the reduced data from the capacitor gauge. 
illustrates the response of the free surface of the target that might be observed by a capacitor gauge.

The case illustrated corresponds to an ideal elastic-plastic material. The shock that accelerates the free surface is divided into elastic and plastic components moving nearly at velocities

$$
C_{e 1}=\sqrt{\frac{B+4 G / 3}{\rho_{0}}} \text { and } C_{0}=\sqrt{B / \rho_{0}} \text {, }
$$

respectively, where $B$ is the bulk modulus, $G$ the shear modulus, and $\rho_{0}$ the density. Similarly, the rarefaction wave that decelerates the free surface should be divided into elastic and plastic waves, with a "shoulder" lying between the two. However, while the two-wave structure is often observed in the acceleration wave, the two-wave rarefaction structure is never observed in uranium and is seldom seen in other engineering metals. We propose that this phenomenon is evidence of the Bauschinger effect.

There is an important philosophical point. Viscous or strain rate effects can be important in a dynamic event such as a plate impact. However, we account first for known static effects before invoking viscous effects. We find that we can account for much of the data and that the residual differences that could result from viscous effects are small.

In the following sections we present quasi-static measurements of the Bauschinger effect and describe a model based on these data that can be incorporated in a hydrodynamic code. We then compare data from plate-impact experiments with the predictions of the model and draw some conclusions about modeling release paths.

$$
\text { QUASI-STATIC DATA }
$$

We conducted a series of tests on uranium specimens to obtain quasistatic measurements. The uranium we used was standard pure D-38 prepared by Union Carbide, ${ }^{*}$ Oak Ridge, ${ }^{3}$ and machined and further annealed dead soft at LLL. Specimens were placed in a specially designed apparatus that subjected

\footnotetext{
*

Reference to a company or product name does not imply approval or recommendation of the product by the University of California or the U.S. Energy Research \& Development Administration to the exclusion of others that may be suitable.
} 
them to uniaxial stress. ${ }^{4}$ The material was initially loaded in both tension and compression; however, the behavior was identical for both cases. (In the plate-impact experiments, compression occurs first.)

Data obtained for initial tensile loading is reduced to true deviator stress vs deviator strain and presented in Fig. 3. Figure 3 shows three different experiments, with specimens loaded to strains of 1, 5, and $10 \%$. To describe these data, we must use both work-hardening and the Bauschinger effect. We do not attempt to develop any fundamental theory for either. Work-hardening is often represented as a dependence of the yield stress on equivalent plastic strain, not because such a dependence is suggested by a theory of dislocation tangles, but because it works. The Bauschinger effect can be attributed to dislocation interactions, formation of slip bands, twinning, or anisotropic grains. Whatever it may be, we wish only to find a reasonable way to represent the unloading paths.

The raw data are sufficiently precise to be differentiated. We can define an effective shear modulus as

$$
G_{\text {eff }}=\frac{1}{2} \frac{d S_{1}}{d \varepsilon_{1}} .
$$

Figure 4 is a plot of the effective shear modulus versus $S_{1} / s_{1}$ max , where $\mathrm{S}_{1}{ }^{\mathrm{max}}$ is the maximum value of $\mathrm{S}_{1}$ upon loading. $\mathrm{S}_{1}{ }^{\max }$ is related to the yield stress when unloading begins; it is two-thirds the yield strength in uniaxial strain. Within the scatter there appears to be a single curve for all three experiments. We do not maintain this interpretation is unique, but it does lead to a very simple model.

MODEL FOR HYDRODYNAMIC CODE

Figure 4 suggests a particularly simple picture of the Bauschinger effect that can be incorporated into a hydrodynamic code. We generalize from the ideal elastic-plastic release path with a constant shear modulus to a curve path described by a variable effective shear modulus, $\mathrm{G}_{\text {eff }}\left(\mathrm{S}_{1} / \mathrm{S}_{1}{ }^{\mathrm{max}}\right)$. If we maintain the yield model unmodified, this argument is bounded by \pm 1 . 


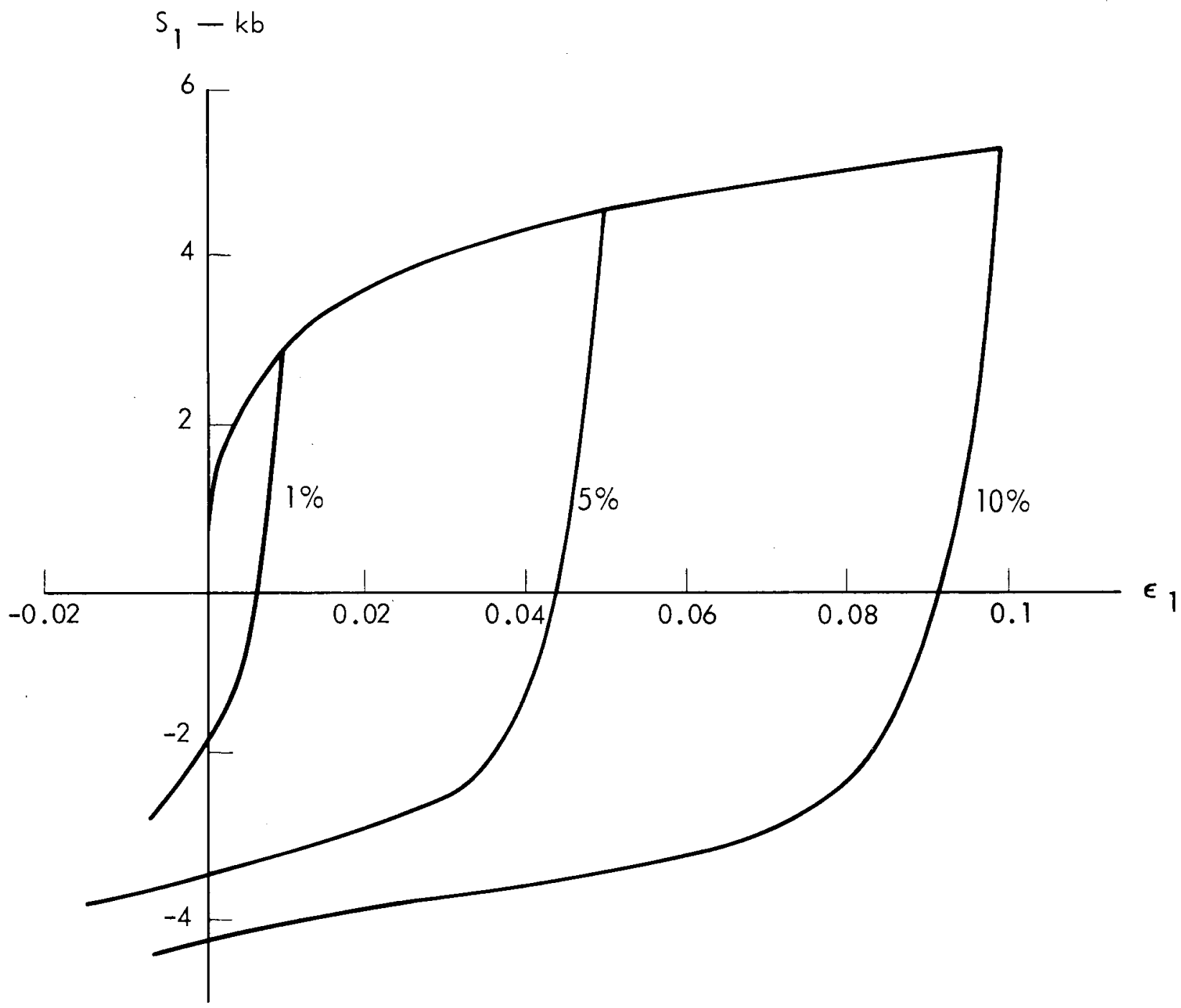

Fig. 3. Measured stress deviator vs strain deviator for uranium at different strains. 


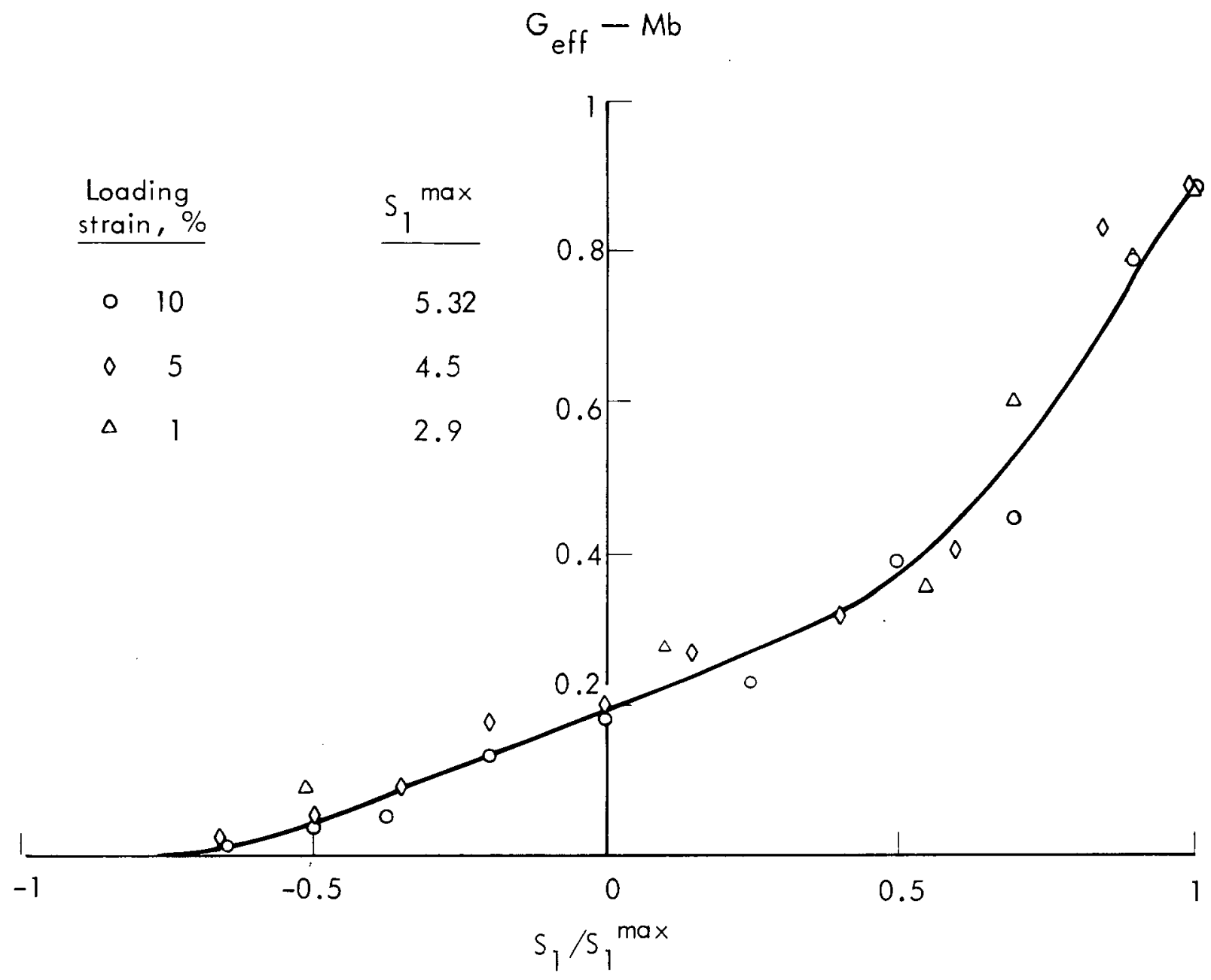

Fig. 4. Interpretation of Bauschinger effect for use in computer model. The curve is fit to the data. 
Note that the rarefaction wave has a velocity

$$
C=\frac{\sqrt{B+4 G_{\text {eff }} / 3}}{\rho} .
$$

Since $G_{\text {eff }}$ will vary from the real shear modulus, $G_{0}$, at unloading to something very small at reverse yield, the two-wave structure of the rarefaction wave will be eliminated. Rather, the rarefaction wave will be continuously dispersed between elastic and bulk wave speeds. We shall see that this improves agreement with dynamic measurements.

We have incorporated into the one-dimensional hydrodynamic code $\mathrm{KO}^{5} \mathrm{a}$ model in which $\mathrm{G}_{\text {eff }}\left(\mathrm{S}_{1} / \mathrm{S}_{1}{ }^{\mathrm{max}}\right.$ ) is approximated by two linear splines (see Fig. 5). To specify the path, only three parameters need to be given: the values of $G_{\text {eff }}$

1. at first release, normally $G_{0}$ :

2. at crossing the hydrostat, that is, at $S_{I}=0, G_{\text {eff }}(0)=G_{I}$; and

3. at reverse yield, $G_{\text {eff }}(-1)=G_{2}$, normally $G_{2}=0$.

Since normally $G_{\text {eff }}(+1)=G_{0}$ and $G_{\text {eff }}(-1)=G_{2}=0$, this is essentially a one-parameter model for the Bauschinger effect.

We obtain a reasonable fit to the quasi-static data with $\mathrm{G}_{1}=0.15 \mathrm{Mb}$, as shown in Fig. 6. We note that conditions of uniaxial strain occur in the code, while the quasi-static experiments were carried out under uniaxial stress. These effects have been accounted for.

A few other features must be added to specify the model completely. The path is independent of whether the initial load is tensile or compressive, in agreement with experiment. The effective shear modulus is never allowed to be less than the current slope of the work-hardening curve, as indicated qualitatively by the data. Irreversibility is maintained; if in the course of the Bauschinger path the strain rate is reversed, the shear modulus reverts to $G_{0}$ (indicated by the arrow in Fig. 6). Finally, the model requires that a small plastic strain threshold be exceeded before the model becomes operationa1.

The Appendix discusses input to the model as implemented in KOVEC. 5 


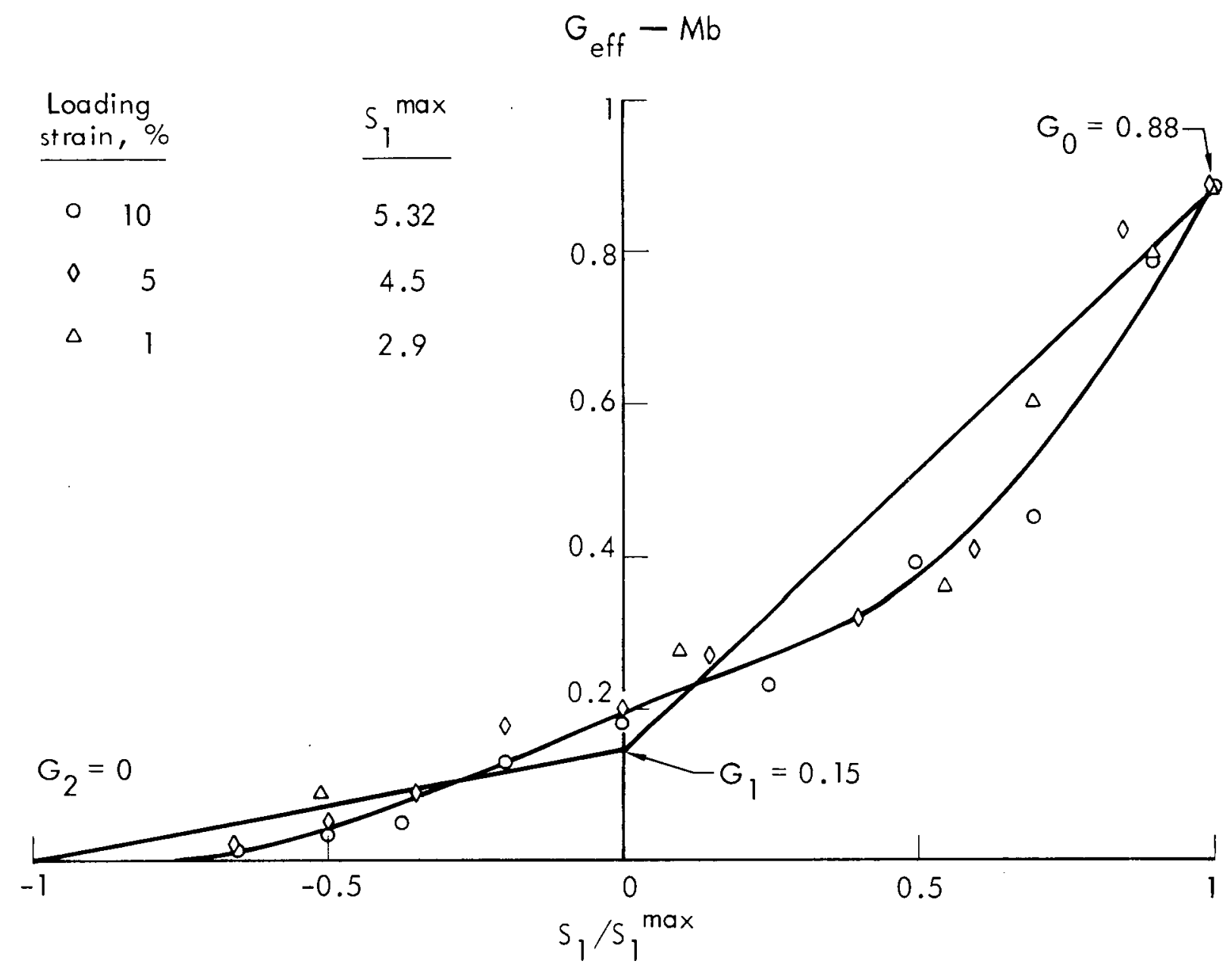

Fig. 5. Model's approximation of Bauschinger effect. 


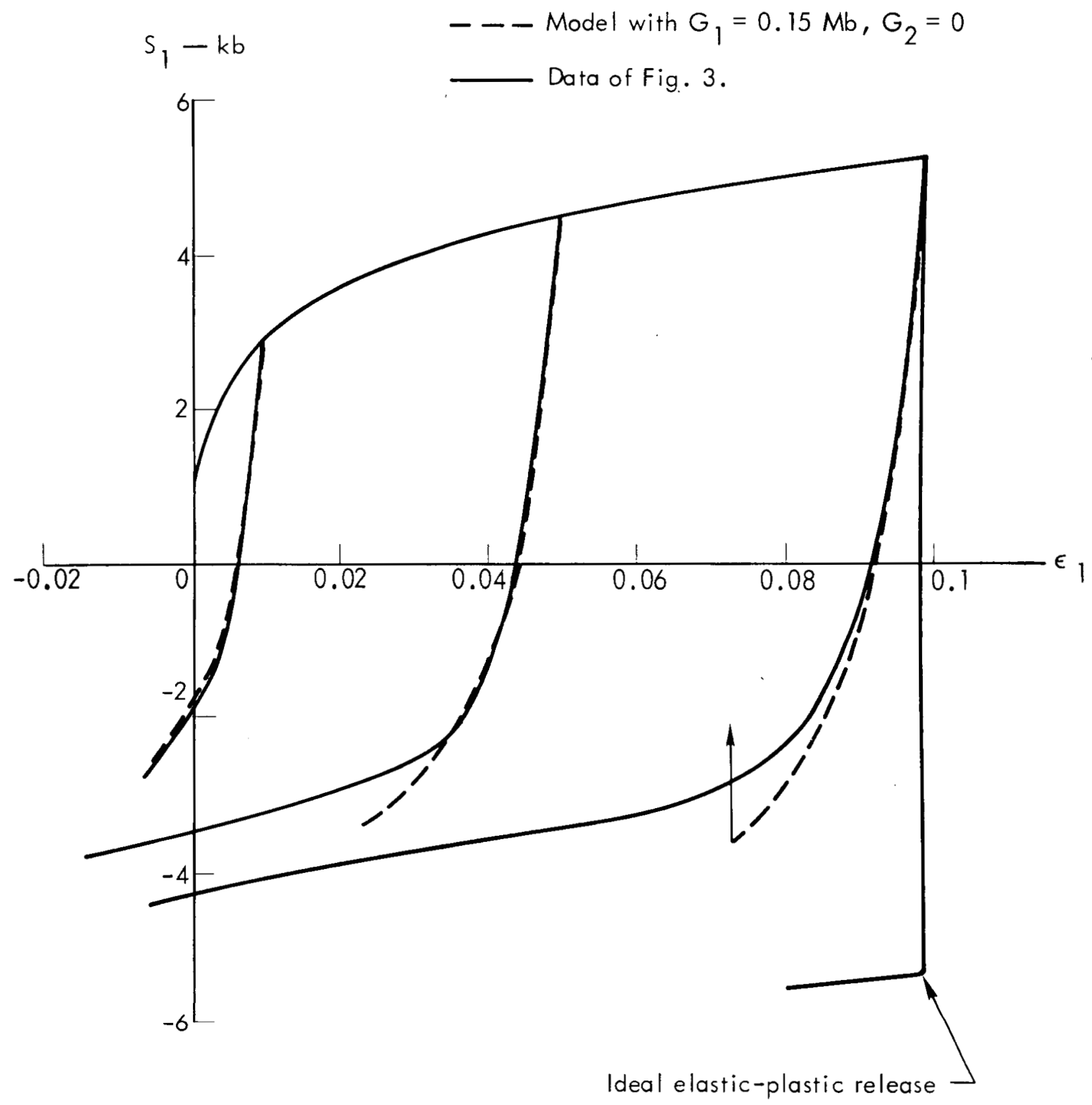

Fig. 6. Comparison of model with static experiment shown in Fig. 3. 
COMPARISON WITH DYNAMIC DATA

D. Banner of LLL has carried out a series of piate-impact experiments in uranium. Some of these experiments were instrumented with a capacitor gauge to measure the free-surface velocity of the target as a function of time. In one such experiment flyer plate, $0.3029 \mathrm{~cm}$ thick, was fired from a $10-\mathrm{cm}$ gun to strike a target plate, $0.6019 \mathrm{~cm}$ thick, at a velocity of $0.0073 \mathrm{~cm} / \mu \mathrm{s}$. Figure 7 compares the results with a simulation made with an elastic-plastic model without any Bauschinger effect. The material properties used in the simulation are:

$$
\begin{aligned}
& \text { - } \rho-19.04 \mathrm{~g} / \mathrm{cm}^{3} \\
& \text { - } \mathrm{C}_{0}-0.248 \mathrm{~cm} / \mu \mathrm{s} \\
& \text { - } \mathrm{S}-1.53 \\
& \text { - } \gamma-2.42 \\
& \text { - } \mathrm{G}_{0}-0.87 \mathrm{Mb} \\
& \text { - } \mathrm{Y}_{0}-0.009 \mathrm{Mb}
\end{aligned}
$$

A Grüneisen equation of state was used along with a sophisticated elasticplastic model with work-hardening. ${ }^{6}$ The density, bulk sound speed, and shear modulus were obtained independently.

This experiment was at low enough velocity to be uncomplicated by spall in the target. The second velocity peak springs from the second reverberation of the stress wave in the target and occurs before two-dimensionality would affect the data. In the simulation, there is no elastic-plastic shoulder on release because the peak velocity is too low compared to the velocity of the precursor. The feature that resembles a shoulder on the rarefaction wave is a reflection of the elastic precursor from the flier back surface.

The data disagree with the simulation in two respects. First, the two-wave structure of the initial acceleration is smeared. This effect almost certainly results from viscosity or strain rate phenomena, phenomena that were not included in the simulation. The value of the initial yield strength in the simulation was chosen to agree with other shots that show an elastic precursor more clearly. " Second, the initial deceleration of the free surface caused by the rarefaction is badly in error. The agreement deteriorates as time goes on.

\footnotetext{
"The magnitude of the yield strength $(9 \mathrm{~kb})$ is higher than the static experiments, either because the material in the quasi-static experiments was annealed dead soft and the plates in the impact experiment has been somewhat work-hardened, or because of dynamic effects, or both.
} 


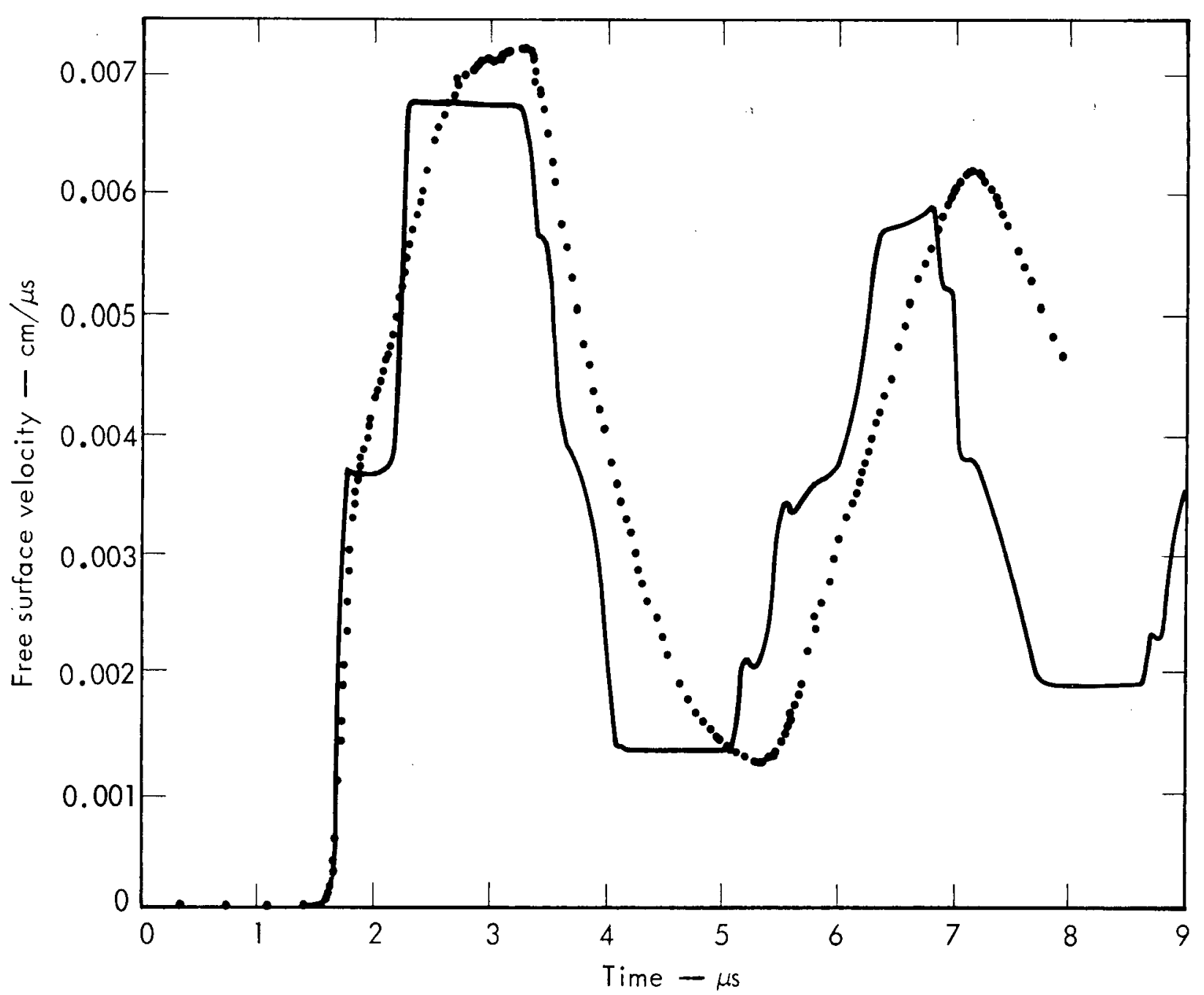

Fig. 7. Comparison of plate-impact experiment with ideal elastic-plastic simulation. The dots represent reduced data, with the impact time normalized to 0 . The solid line is the simulation. 
We try to account for the latter discrepancy between the data and the calculation of the rarefaction by including a Bauschinger effect. In our view, strain rate effects can be sensibly considered only after important static phenomena have been handled.

Figure 8 shows the KO simulation of the experiment, with the Bauschinger model, compared to the same reduced data. The improved agreement is striking. The first rarefaction wave and second reverberation are calculated much more accurately. The Bauschinger model affects the peak free-surface velocity because the material near the free surface is first loaded by the elastic precursor, released, and then loaded by the plastic wave. The absolute magnitude of the peak in the data is uncertain to about $5 \%$; the exact agreement in this case is fortuitous.

We chose this experiment to illustrate our work on the Bauschinger effect because the Bauschinger effect in uranium is large and the results are most striking. However, we must emphasize that the improved agreement is typical of that seen in some 20 plate-impact experiments, where the rarefaction wave is sensitive to the Bauschinger effect.

We have also applied the model to the materials shown in Table 1 . For most of these materials, the model with $G_{1}=G_{0}$ and $G_{2}=0$ gives good agreement;

Table 1. Bauschinger properties for some materials ${ }^{a}$.

\begin{tabular}{|c|c|c|c|c|}
\hline \multirow[b]{2}{*}{ Material } & \multicolumn{4}{|c|}{ Property } \\
\hline & $\begin{array}{c}Y_{0} \\
(k b)\end{array}$ & $\begin{array}{c}\mathrm{G}_{0} \\
(\mathrm{Mb})\end{array}$ & $\begin{array}{c}G_{1} \\
(\mathrm{Mb})\end{array}$ & $\begin{array}{c}\mathrm{G}_{2} \\
(\mathrm{Mb})\end{array}$ \\
\hline Uranium & 9. & 0.87 & 0.15 & 0 \\
\hline $\begin{array}{l}\text { Copper } \\
\text { (OFHC) }\end{array}$ & 1.2 & 0.477 & 0.477 & 0 \\
\hline $\begin{array}{l}\text { Aluminum } \\
(6061-T 6)\end{array}$ & 2.9 & 0.276 & 0.276 & 0 \\
\hline Tantalum & 7.7 & 0.69 & 0.69 & 0 \\
\hline Alpha titanium & 11.5 & 0.474 & 0.2 & 0 \\
\hline $\begin{array}{l}\text { Steel } \\
\text { (Stainless 304) }\end{array}$ & 4 & 0.77 & 0.77 & 0 \\
\hline $\begin{array}{l}\text { Stee1. } \\
(4330 \mathrm{~V})\end{array}$ & 13.5 & 0.81 & 0.81 & 0 \\
\hline Alpha plutonium & 9.6 & 0.422 & 0.422 & 0 \\
\hline
\end{tabular}

$a_{\text {These numbers were obtained by fitting the available dynamic profiles. The }}$ data for aluminum and titanium were obtained from Ref. 7 . 


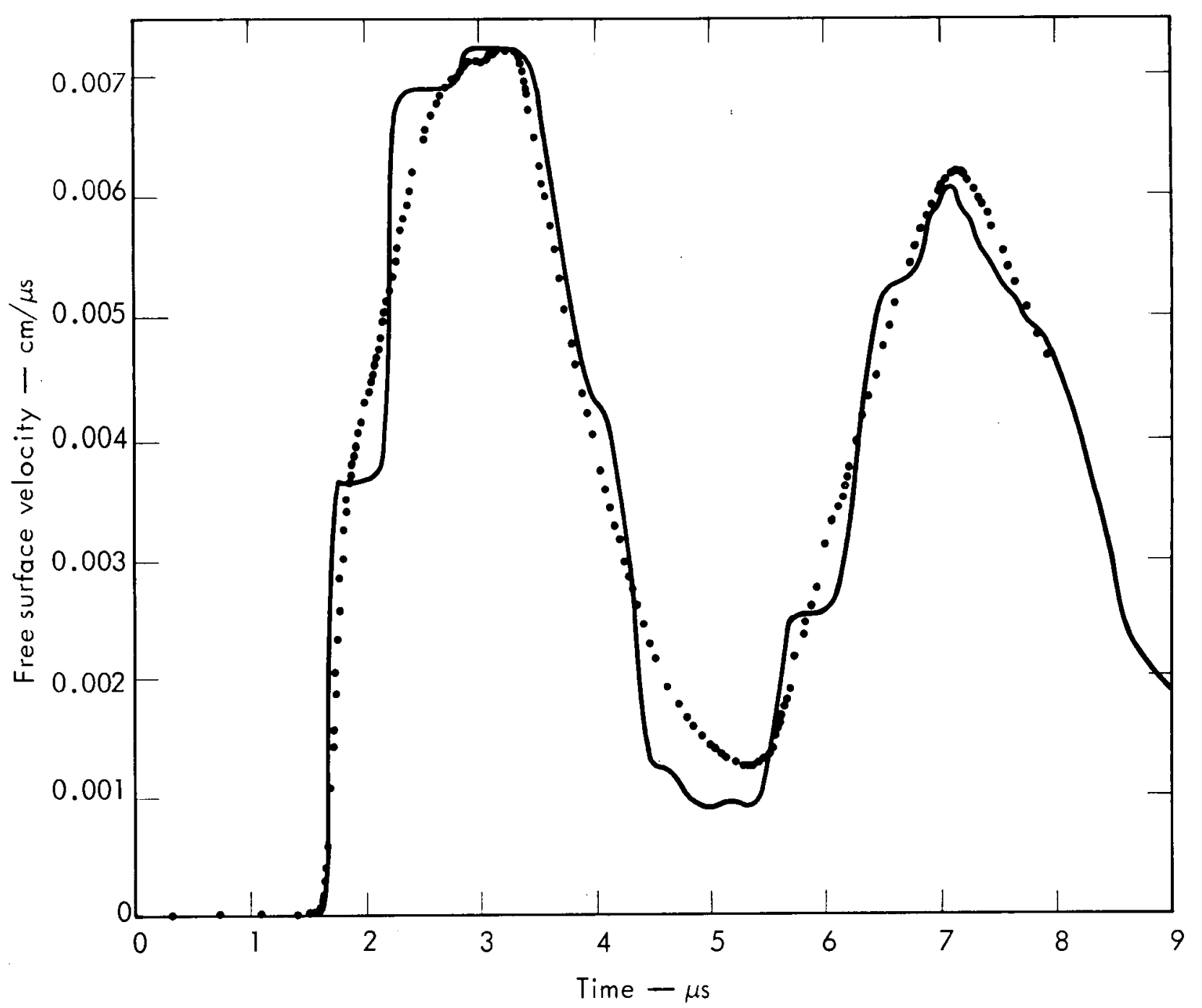

Fig. 8. Comparison of plate-impact experiment with Bauschinger-model simulation. The dots represent reduced data; the solid line is the simulation. 
i.e., the first aspect of the Bauschinger effect is small or absent. For aluminum and copper, this conclusion is supported by quasi-static measurements $^{7}$. In fact, this choice of parameters always appears to be a better approximation than the ideal elastic-plastic release path, which has $G_{1}=G_{2}=G_{0}$.

\section{CONCLUSIONS}

We believe the Bauschinger effect to be an important aspect in the rarefaction waves of uranium and other engineering metals. We have developed a model of the effect that substantially improves agreement with data from plate-impact experiments. The model we have proposed represents the release path by an effective shear modulus, $G_{\text {eff }}$, that varies. To simplify modeling, we have dropped the distinction between elastic and plastic strain in the Bauschinger regime. We have not attempted to justify the model with any fundamental theory.

We find that the procedure of modifying the slope - shear modulus - is extremely powerful and particularly smooth and gentle. Furthermore, the evidence so far leads us to believe that the principal parameter, $G_{1}$, is nearly a material property. Thus we assert that the model will predict the results of future plate-impact experiments.

We have simulated other materials, notably copper, aluminum, and tantalum, besides uranium. Although the Bauschinger effect is smaller, we can make noticeable improvements in simulating symmetric plate-impact experiments for these materials when we use this model. We are convinced of the general utility of this model to simulate the Bauschinger effect in many engineering metals.

\section{ACKNOWLEDGMENT}

It is a pleasure to acknowledge helpful discussion with D. Steinberg and D. Banner and the willing assistance of the KO group, S. J. French, C. Hunter and J. Woodruff. 
REFERENCES

1. M. Wilkins, Calculations of Elastic-Plastic Flow, Lawrence Livermore Laboratory, Rept. UCRL-7322 Rev. 1 (1969).

2. S. Cochran, Preliminary Report on a Model for Incipient Spall, Lawrence Livermore Laboratory, Rept. UCID-16676 (1975).

3. Recommended Process Procedure, Union Carbide, Oak Ridge, Tennessee, Rept. SPY-007 (1975).

4. K. Hoge, R. Brady, and R. Cortez, A Tension-Compression Test Fixture to Determine Bouschinger Effect, Lawrence Livermore Laboratory, Rept. UCRL-73675 Rev. 1 (1972).

5. For information about KO or KOVEC, contact J. Woodruff, Lawrence Livermore Laboratory.

6. For more details about the equation of state and elastic-plastic model used in this simulation, contact D. Steinberg, Lawrence Livermore Laboratory .

7. D. Christman et al. Measurements of Dynamic Properties of Materials (Materials and Structures Laboratory, General Motors, Warren, Michigan, 1972), vols. III, IV, and V. 


\section{APPENDIX}

Shortly after the release of this document, the Bauschinger model will become active in the public version of KOVEC. Table 1 in the text shows some of the materials to which the model has been calibrated. For many materials, including five of seven in Table 1 , we find that the parameters $G_{1}=G_{0}$ and $G_{2}=0$ give good agreement. For these materials, the model has no independent parameters. For most other materials, the model reproduces elasticplastic behavior; that is, $G_{1}=G_{2}=G_{0}$. Thus, the user should see no effect for these cases.

To review the input - there are three material properties, $G_{1}, G_{2}$, and FTWIN. In addition, there is a logic switch, NRLS. When NRLS $=0$, the mode1 is off; when NRLS $=1$, the model is on. The default for NRLS will be 1 (ON) after this document is published. The material properties may be input by the user by equation of state or by region:

\begin{tabular}{ll} 
Equation of State & Region \\
\hline FTWIN & FTWINR \\
G1 & G1R \\
G2 & G2R
\end{tabular}

There are default values for all standard materials used in KOVEC. 5 GI is the value of the effective shear modulus upon crossing the hydrostat, while $G 2$ is the value at reverse yield. FTWIN is a factor that modifies the initial value of the effective shear modulus so that $G_{\text {eff }}(+1)=$ FTWIN*G $_{0}$. Current1y, the default is FTWIN = 1 for a11 materials. 


\section{NOTICE}

"This report was prepared as an account of work sponsored by the United States Government. Neither the United States nor the United States Energy Research \& Development Administration, nor any of, their employees, nor any of their contractors, subcontractors, or their employees, makes any warranty, express or implied, or assumes any legal liability or responsibility for the accuracy, completeness or usefulness, of any information, apparatus, product or process disclosed, or represents that its use. would not infringe privately-owned rights."

Printed in the United States of America

$$
\text { Available from }
$$

National Technical Information Service U.S. Department of Commerce 5285 Port Royal Road Springfield, VA 22161

Price: Printed Copy $\$$; Microfiche $\$ 2.25$

\begin{tabular}{ccc}
$\begin{array}{c}\text { Domestic } \\
\text { Price }\end{array}$ & $\frac{\text { Page Range }}{1}$ & $\begin{array}{c}\text { Domestic } \\
\text { Price }\end{array}$ \\
\hline 3.50 & $326-350$ & 10.00 \\
4.00 & $351-375$ & 10.50 \\
4.50 & $376-400$ & 10.75 \\
5.00 & $401-425$ & 11.00 \\
5.25 & $426-450$ & 11.75 \\
5.50 & $451-475$ & 12.00 \\
6.00 & $476-500$ & 12.50 \\
7.50 & $501-525$ & 12.75 \\
7.75 & $526-550$ & 13.00 \\
8.00 & $551-575$ & 13.50 \\
9.00 & $576-600$ & 13.75 \\
9.25 & $601-$ up & $*$ \\
9.75 & &
\end{tabular}

*Add $\$ 2.50$ for each additional 100 page increment from 601 to 1,000 pages: add $\$ 4.50$ for each additional 100 page increment over 1,000 pages 


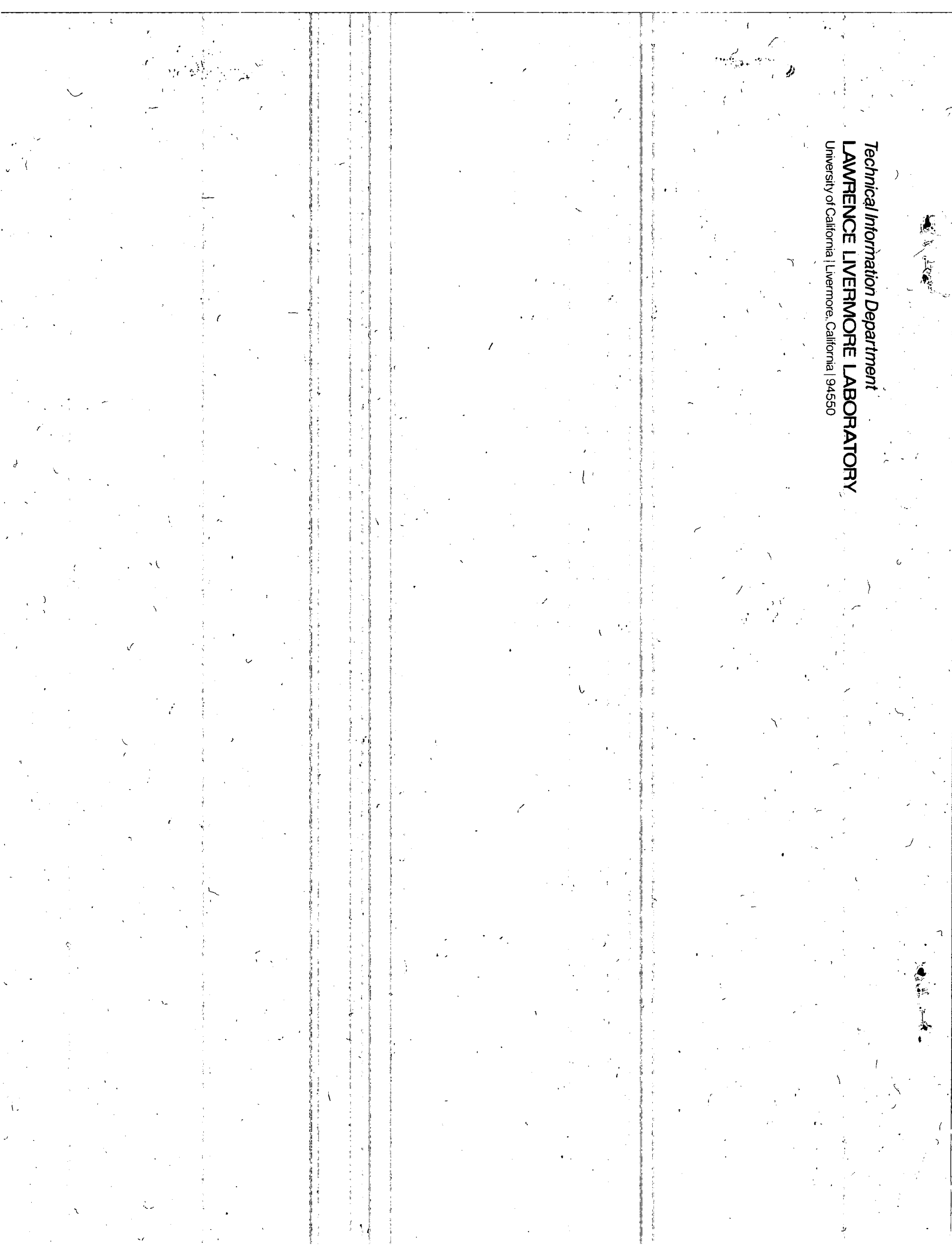

